\title{
Preliminary results of fetal cardiac bypass in nonhuman primates
}

\author{
Akio lkai, MDa \\ R. Kirk Riemer, $\mathrm{PhD}^{\mathrm{a}}$ \\ Chandra Ramamoorthy, $\mathrm{MD}^{\mathrm{b}}$ \\ Sunil Malhatra, MD \\ Lydia Cassorla, MD \\ Gabriel Amir, MD \\ Frank L. Hanley, MDa \\ V. Mohan Reddy, $M D^{a}$
}

From the Department of Cardiothoracic Surgery, Division of Pediatric Cardiac Surgery, ${ }^{a}$ and the Department of Anesthesiology, Division of Pediatric Cardiac Anesthe-

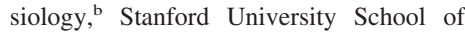
Medicine, Stanford, Calif, the Department of Surgery, New York University Medical Center, ${ }^{\mathrm{c}}$ New York, NY, and the Department of Anesthesiology, University of California San Francisco, ${ }^{\mathrm{d}}$ San Francisco, Calif.

Supported by funding from the National Institutes of Health, award RO1 HL43357.

Read at the Eighty-fourth Annual Meeting of The American Association for Thoracic Surgery, Toronto, Ontario, Canada, April 25-28, 2004.

Received for publication April 23, 2004; revisions received Sept 1, 2004; accepted for publication Sept 7, 2004.

Address for reprints: V. Mohan Reddy, MD, Department of Cardiothoracic Surgery, Division of Pediatric Cardiac Surgery, Stanford University, 300 Pasteur Dr, Falk CVRC, Palo Alto, CA 94305-5407 (E-mail: vmreddy@Stanford.edu).

J Thorac Cardiovasc Surg 2005;129:175-81 $0022-5223 / \$ 30.00$

Copyright (c) 2005 by The American Association for Thoracic Surgery

doi:10.1016/j.jtcvs.2004.09.003
Objective: Fetal cardiac surgery has potential benefits for treatment of some congenital heart defects. However, placental dysfunction as a result of fetal bypass, fetal stress, and fetal exposure to external milieu needs to be overcome to optimize the outcomes of fetal cardiac bypass. In this study we evaluated the technical feasibility of cardiac bypass in the nonhuman primate fetus and the efficacy of different anesthetic approaches.

Methods: Twelve baboon fetuses, average gestation $146 \pm 8$ days and weight $696 \pm$ $184 \mathrm{~g}$, were used. Three fetuses were excluded from the study because of nuchal cord presentations. The animals were separated into two anesthesia groups: isoflurane $(\mathrm{n}=$ 6) and fentanyl and midazolam $(n=3)$. A miniature roller pump circuit without oxygenator was used for fetal bypass for 30 minutes. No blood transfusion was performed. Fetal blood gas samples were collected before bypass, during bypass, and at 15 and 60 minutes after bypass.

Results: All fetuses in the isoflurane group were successfully placed on the cardiac bypass circuit. However, 2 animals in the fentanyl and midazolam group were not placed on the bypass circuit because of sustained elevation in maternal uterine tone. All maternal baboons survived. Of the 6 fetuses in the isoflurane group, 5 survived for 60 minutes; however, placental function continued to deteriorate after bypass $\left(\mathrm{PaO}_{2} 33 \pm 3 \mathrm{~mm} \mathrm{Hg}\right.$ before bypass, $23 \pm 6 \mathrm{~mm} \mathrm{Hg} 15$ minutes after, and $18 \pm 9$ mm Hg 60 minutes after).

Conclusion: The technical feasibility of cardiac bypass in nonhuman primate fetuses weighing less than $1000 \mathrm{~g}$ was confirmed. Isoflurane anesthesia appears to be superior to fentanyl and midazolam anesthesia for fetal cardiac surgery because of adequate uterine relaxation.

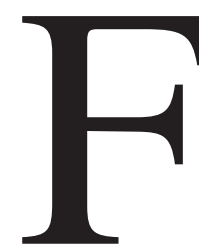

etal cardiac surgery is a challenging innovation for treatment of complex cardiac anomalies that start out as relatively simple lesions early during gestation. ${ }^{1}$ Intracardiac operations, however, require that the fetus be placed on extracorporeal circulation. We have successfully achieved good fetal survival after fetal cardiac bypass in the lamb model by using an innovative bypass circuit and minimizing fetal exposure. ${ }^{2,3}$ However, placental dysfunction caused by both hemodynamic factors and generalized fetal stress in the procedure induces fetal morbidity that restricts the success of this surgical procedure. ${ }^{1,4-8}$ In our previous reports, ${ }^{2,3,9,10}$ we explored the use of continuous ketamine infusion for anesthesia in our attempt to 
TABLE 1. Fetal and maternal baboon data, including prebypass arterial blood gas values, and outcomes

\begin{tabular}{|c|c|c|c|c|c|c|c|c|c|c|}
\hline & \multirow{2}{*}{$\begin{array}{c}\text { Anesthetic } \\
\text { method }\end{array}$} & \multicolumn{4}{|c|}{ Maternal } & \multicolumn{4}{|c|}{ Fetal } & \multirow[b]{2}{*}{ Outcome } \\
\hline & & Weight (kg) & $\mathrm{pH}$ & $\mathrm{PaCO}_{2}$ & $\mathrm{PaO}_{2}$ & Weight (g) & pH & $\mathrm{PaCO}_{2}$ & $\mathrm{PaO}_{2}$ & \\
\hline 1 & Isoflurane & 14.3 & 7.43 & 38 & 538 & 603 & 7.32 & 46.1 & 38 & Observed for $2 \mathrm{~h}$ postbypass \\
\hline 2 & Isoflurane & 14 & 7.5 & 33 & 480 & 780 & 7.33 & 53 & 31 & \\
\hline 3 & Isoflurane & 14.2 & 7.38 & 41 & 247 & 490 & 7.29 & 58 & 31 & \\
\hline 4 & Isoflurane & 17 & 7.47 & 32 & 466 & 1000 & 7.32 & 49 & 31 & \\
\hline 5 & Isoflurane & 15.8 & 7.46 & 27 & 350 & 672 & 7.34 & 39 & 34 & \\
\hline 6 & Isoflurane & 16.3 & 7.46 & 34 & 452 & 585 & 7.32 & 49 & 31 & Die 20 min postbypass \\
\hline \multicolumn{11}{|l|}{$1-6$} \\
\hline Mean & & 15.3 & 7.45 & 34 & 422 & 688 & 7.32 & 49 & 33 & \\
\hline SD & & 1.2 & 0.04 & 4 & 96 & 165 & 0.02 & 6 & 3 & \\
\hline 7 & $\begin{array}{r}\text { Fentanyl and } \\
\text { midazolam }\end{array}$ & 15.2 & 7.51 & 27 & 505 & 474 & 7.09 & 47 & 21 & Failed to go on bypass \\
\hline 8 & $\begin{array}{r}\text { Fentanyl and } \\
\text { midazolam }\end{array}$ & 19.3 & 7.48 & 30 & 484 & 938 & 7.08 & 61 & 16 & Died after bypass \\
\hline 9 & $\begin{array}{r}\text { Fentanyl and } \\
\text { midazolam }\end{array}$ & 17.4 & 7.43 & 30 & 618 & 727 & 7.12 & 82 & 15 & Failed to go on bypass \\
\hline \multicolumn{11}{|l|}{$7-9$} \\
\hline Mean & & 17.3 & 7.47 & 29 & 536 & 713 & $7.10^{*}$ & 63 & $17 \dagger$ & \\
\hline SD & & 2.1 & 0.04 & 2 & 72 & 232 & 0.02 & 18 & 3 & \\
\hline
\end{tabular}

$* P=.02$ versus isoflurane group.

$\dagger P=.025$ versus isoflurane group.

develop fetal cardiac bypass techniques. However, it is well known that ketamine does not suppress the catecholamine release that contributes to the fetal stress response. Because fetal lambs apparently do not possess central nerve system narcotic receptors, the sheep is not a suitable animal model for investigation of the efficacy of clinically relevant narcotic anesthesia. We therefore have taken the next step toward the ultimate goal of achieving human fetal intracardiac surgery by exploring techniques for safe and effective fetal cardiac bypass in a nonhuman primate model. Fetal blood volume is a critical parameter in cardiac bypass, and the fetal baboon size (and thus blood volume) more closely approximates that of human beings than do fetal blood volumes of other available species. Currently isoflurane is the most popular anesthetic agent for fetal surgery because of the desirable side effect of uterine relaxation ${ }^{11,12}$ and its simple and reliable delivery by maternal inhalation. Fentanyl is a proven effective anesthetic agent for suppression of surgical stress in neonatal cardiac surgery. In this study we evaluated the response of the nonhuman primate fetus to cardiac bypass, comparing the efficacies of isoflurane and fentanyl anesthesia.

\section{Methods}

A total of twelve baboon fetuses, average gestation $146 \pm 8$ days (80\% gestation) and weight $696 \pm 184 \mathrm{~g}$, were used. The maternal baboon fasted for 8 hours. After premedication of the animal with ketamine $(10 \mathrm{mg} / \mathrm{kg})$ and atropine $(0.04 \mathrm{mg} / \mathrm{kg})$ by intramuscular injection, peripheral intravenous access and an intra-arterial mon- itoring catheter were established, and lactated Ringer solution was administered intravenously.

The baboon was placed in the supine position on a warming blanket. Oxygen at $100 \%$ was administered, and the heart rate and oxygen saturation were continuously monitored by pulse oximetry. After the induction of anesthesia, the baboon was intubated and ventilated with $100 \%$ oxygen and volume-control to maintain $\mathrm{PaCO}_{2}$ in a physiologic range.

\section{Anesthetic and Surgical Protocols}

The animals were separated into the isoflurane $(n=6)$ and fentanyl and midazolam $(n=3)$ groups. Three fetuses were excluded from the study because of nuchal cord presentations.

All subjects were initially anesthetized with $1 \%$ to $2 \%$ isoflurane. In the isoflurane group, vapor anesthesia was continued without interruption. Once intravenous access to the fetus had been obtained, the anesthesia modality was switched for the fentanyl and midazolam group. In this group, anesthesia was induced individually for mother and fetus by infusion of fentanyl at $50 \mu \mathrm{g} / \mathrm{kg}$ and midazolam at $0.1 \mathrm{mg} / \mathrm{kg}$ and maintained with continuous infusion of fentanyl at $10 \mu \mathrm{g} /(\mathrm{kg} \cdot \mathrm{h})$ and midazolam at $0.1 \mathrm{mg} /(\mathrm{kg} \cdot \mathrm{h})$. Total dose of fentanyl given for maternal baboon was $76 \pm 31 \mu \mathrm{g} / \mathrm{kg}$.

After laparotomy, a low transverse hysterotomy was made, taking care to avoid the placenta. In the initial few studies, the fetuses were totally exteriorized from the uterus, and the fetal head was enclosed in a surgical glove containing warm saline solution to prevent air breathing. In the later two studies, the fetus was only partially exteriorized. In the fentanyl and midazolam group, a peripheral intravenous line was established in the partially exteriorized extremity for administration of drugs. Fetal sternotomy and 

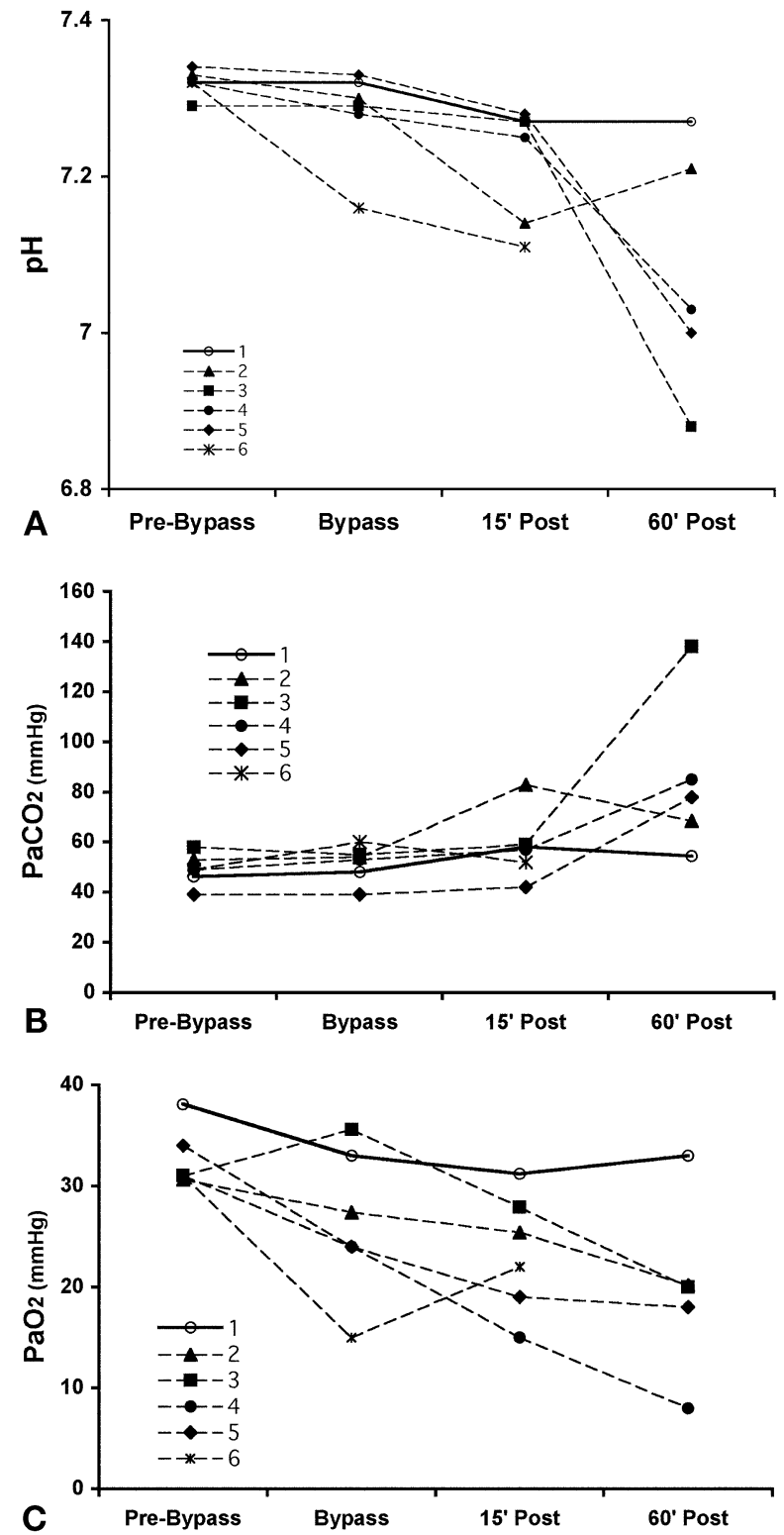

Figure 1. Changes in fetal arterial blood gas values with cardiac bypass in isoflurane group: $\mathrm{pH}(\mathrm{A}), \mathrm{PaCO}_{2}$ (B), and $\mathrm{PaO}_{2}$ (C). Each line indicates values for individual fetus. Solid line indicates fetus (case 1) in which placental dysfunction was suppressed.

pericardiotomy were performed. A 22-gauge arterial catheter was inserted in the carotid artery. Purse-string sutures were placed on the main pulmonary artery and the right atrium with 5-0 polypropylene sutures (Ethicon, Inc, Somerville, NJ). A 300-U/kg dose of heparin was given intravenously to the fetus through the right atrium. The right atrium was cannulated with a $10 \mathrm{~F}$ ventricular vent cannula (Medtronic DLP, Grand Rapids, Mich). A 14- or 16-gauge angiocatheter was placed in the main pulmonary artery as an arterial cannula. Both arterial and venous cannulas were connected to the bypass circuit, which was filled with 14 to $20 \mathrm{~mL}$ crystalloid solution (Normosol-R; Abbott Laboratories, Abbott

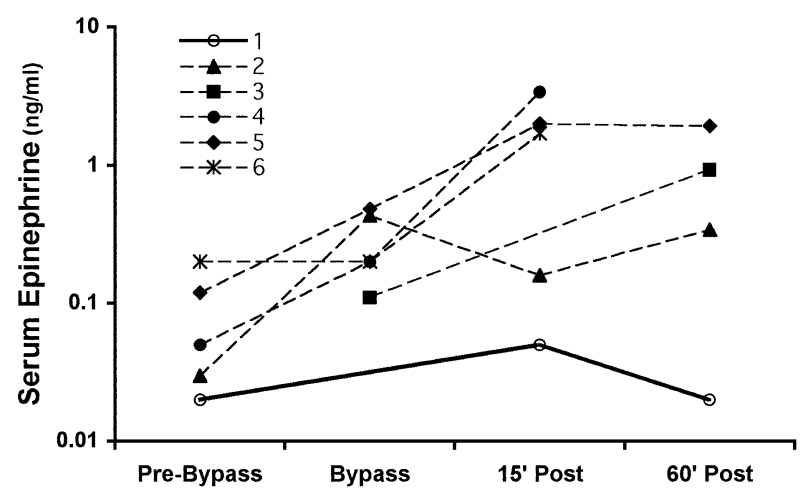

Figure 2. Changes in serum concentration of epinephrine with cardiac bypass in isoflurane group. Each line indicates values for individual fetus. Solid line indicates fetus (case 1) in which placental dysfunction was suppressed.

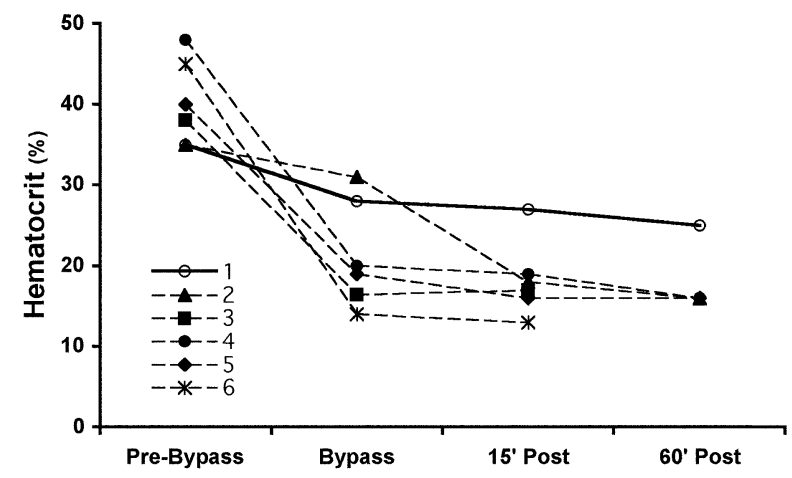

Figure 3. Changes in hematocrit with cardiac bypass in isoflurane group. Each line indicates values for individual fetus. Solid line indicates fetus (case 1) in which placental dysfunction was suppressed.

Park, Ill). No oxygenator was used in the circuit. Pump flows were continuously monitored with an inline ultrasonic flow probe (Transonic Systems, Inc, Ithaca, NY). Maximum achievable pump flow was maintained in each animal $(176 \pm 70 \mathrm{~mL} /[\mathrm{min} \cdot \mathrm{kg}])$. Fetuses were infused at $50 \mathrm{~mL} /(\mathrm{kg} \cdot \mathrm{h})$ with crystalloid solution during bypass to maintain adequate bypass flow and hemodynamics. The fetus was placed on normothermic cardiac bypass for 30 minutes. Cardiac bypass was then discontinued. Heparin was reversed with protamine ( $1 \mathrm{mg} / \mathrm{kg}$ intravenously). The fetus was then monitored for 60 to 120 minutes outside the uterus. No fetus received blood transfusions throughout the study to eliminate any potential adverse effects of adult hemoglobin. Subsequently, the fetus was killed with intravenous pentobarbital sodium $(150 \mathrm{mg} / \mathrm{kg})$ and a fetectomy was performed. Oxytocin (10 IU) was administered to effect delivery of the placenta and prevent continuous bleeding from the uterus.

The hysterotomy and the laparotomy were closed in the usual surgical manner. Cefazolin (15 mg/kg intravenously) was administered after the operation. After full recovery from anesthesia, the baboon was extubated and received standard postoperative care. 


\section{Measurements}

Hemodynamic variables were continuously recorded during the entire study. Maternal blood gas values were measured every 30 minutes. Fetal blood gas values were measured before bypass, 15 minutes into bypass, and at 15 and 60 minutes after bypass. Blood gas values, $\mathrm{pH}$, and hematocrit were measured with a clinical blood gas analyzer (International Technidyne Corp, Andover, Mass). As an indicator of fetal stress, serum epinephrine concentration was measured at the same time point as blood gas values. Blood samples $(1 \mathrm{~mL})$ were drawn through the arterial catheter, placed immediately in a serum tube with separation gel, mixed gently five times in tube, then centrifuged at $2000 \mathrm{rpm}$ for 10 minutes at $4{ }^{\circ} \mathrm{C}$ and stored at $4{ }^{\circ} \mathrm{C}$ until off-site assay (IDEXX Laboratories, Sunnyvale, Calif).

All animals received humane care in compliance with the "Principles of Laboratory Animal Care" formulated by the National Society of Medical Research and the "Guide for the Care and Use of Laboratory Animals" (http://www.nap.edu/catalog/ 5140.html). The experimental protocol was approved by the Institutional Animal Care and Use Committees at the University of California San Francisco and Stanford University.

\section{Statistical Methods}

All values are expressed as mean $\pm \mathrm{SD}$. The Mann-Whitney test was used in comparing the isoflurane group with the fentanyl and midazolam group. The Wilcoxon signed rank test was used to compare the change in blood gas and hemodynamic values before, during, and after cardiac bypass.

\section{Results}

Maternal heart rate, blood pressure, and prebypass blood gas values were normal, and there were no differences between the two anesthetic groups (data not shown). In the fentanyl and midazolam group, however, prebypass fetal arterial blood gas parameters significantly deteriorated relative to the isoflurane group (Table 1). Moreover, all fetuses in the isoflurane group were placed on cardiac bypass; however, only 1 fetus in the fentanyl and midazolam group could be placed on cardiac bypass. The other two fetuses could not be placed on cardiac bypass because of poor blood gas status, which was probably caused by high uterine tone. One fetus in the isoflurane group died 20 minutes into bypass.

\section{Blood Gas Analysis}

Figure 1 demonstrates the change in blood gas parameters. $\mathrm{PaO}_{2}$ decreased steadily after initiation of cardiac bypass to the end of the observation period. $\mathrm{PaCO}_{2}$ was well maintained during cardiac bypass; however, it was increased after bypass, especially at 60 minutes after cessation of bypass. One fetus (case 1) maintained good respiratory function at 60 minutes after the bypass. The blood gas data of this fetus 2 hours after bypass was as follows: $\mathrm{pH} 7.25$, $\mathrm{PaCO}_{2} 62.5 \mathrm{~mm} \mathrm{Hg}$, and $\mathrm{PaO}_{2} 19.2 \mathrm{~mm} \mathrm{Hg}$.

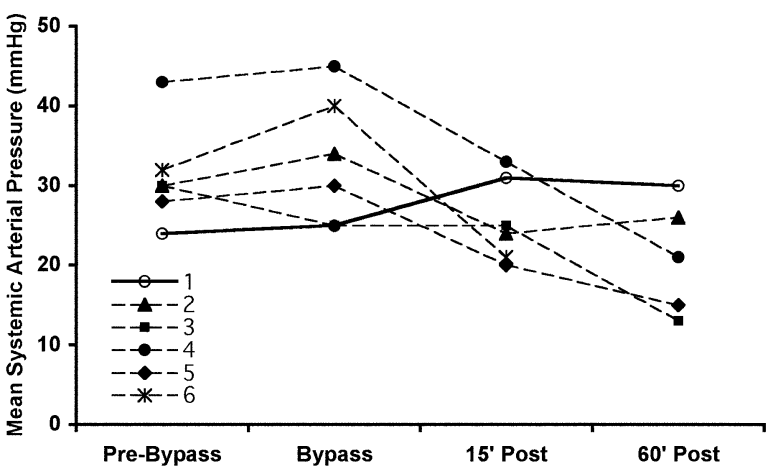

Figure 4. Changes in mean systemic arterial blood pressure with cardiac bypass in isoflurane group. Each line indicates values for individual fetus. Solid line indicates fetus (case 1) in which placental dysfunction was suppressed.

\section{Epinephrine Concentration}

Figure 2 demonstrates the change in serum concentration of epinephrine with bypass. During the entire experiment, the level of epinephrine was increased above the upper range of normal level. Interestingly, the fetus that maintained normal blood gas parameters and high hematocrit (case 1) also maintained low levels $(0.03 \mathrm{ng} / \mathrm{mL})$ of epinephrine, and the level was maintained as long as 2 hours after bypass.

\section{Hemodilution}

Figure 3 shows the changes in hematocrit with bypass. Preoperative hematocrit was $40 \% \pm 5 \%$. After initiation of bypass, hematocrit was significantly decreased to $21 \% \pm$ $7 \%(P=.027$ vs prebypass $)$ as a result of hemodilution and surgical blood loss. After discontinuation of bypass, hematocrit was further decreased to $18 \% \pm 5 \%$ in 15 minutes. One fetus (case 1) lost less blood at the initiation of bypass and maintained a high hematocrit after bypass.

\section{Fetal Blood Pressure}

Figure 4 shows the change in mean systemic arterial blood pressure with bypass. Prebypass mean arterial blood pressure was $31 \pm 6 \mathrm{~mm} \mathrm{Hg}$. After initiation and during bypass, mean arterial blood pressure was maintained; however, it decreased after bypass. The 1 fetus that maintained the pre bypass level of mean arterial blood pressure after cessation of bypass (case 1) also had high hematocrit.

\section{Discussion}

In this study we confirmed that fetal tissue has enough tensile strength to allow instrumentation for cardiac bypass. Furthermore, our experience has provided additional insight into some of the critical variables necessary for the future advancement of fetal cardiac surgical intervention.

Maximizing survival after fetal cardiac surgery requires not only technical expertise but also minimization of the 
fetal stress response, prevention of fetal myocardial depression, and prevention of placental dysfunction. In earlier ovine fetal studies, continuous ketamine infusion was used as an anesthetic agent. ${ }^{2,3,6,9,10}$ However, ketamine does not block the release of catecholamine in response to stress. High doses of the narcotic fentanyl provide effective anesthesia in neonates and infants undergoing cardiac procedures with respect to both blockage of the stress response and maintenance of cardiac function. To evaluate the efficacy of this agent, we administered a combination of fentanyl and midazolam to the mother and fetus individually. However, the combination of these drugs did not provide enough uterine relaxation to prevent the induction of fetal distress from hypoxia before the institution of cardiac bypass. Thus technical factors arose due to lack of adequate fetal exposure. On the other hand, isoflurane is preferred for use in fetal noncardiac surgery because of its uterine muscle-relaxing properties and ease of administration. ${ }^{11,12}$ In our experiments, uterine tone was well managed for fetal manipulation, including exteriorization from and repositioning into the uterus, in the isoflurane group. Isoflurane appears to be quite suitable as an anesthetic agent for fetal cardiac surgery. We have previously reported that placental vasoconstriction in response to endothelin was augmented after fetal cardiac bypass. ${ }^{9}$ Both ketamine and isoflurane can cross the placenta rapidly. ${ }^{13,14}$ In an in vitro study, Boillot and colleagues ${ }^{15}$ reported that isoflurane exerts an indomethacin-like effect on the production of an endothelially derived vasoconstricting cyclooxygenase product, as demonstrated by the reduction in the endothelin 1-induced vascular contraction of isolated rat aorta. On the other hand, clinical doses of ketamine have been found not to affect vasoconstriction in porcine cerebral artery. ${ }^{16}$ These data also support the concept that isoflurane anesthesia is beneficial not only for fetal manipulation in the uterus but also for a possible reduction in placental dysfunction through suppression of eicosanoid mediators of vasoconstriction. However, isoflurane has been reported to depress fetal cardiac function. ${ }^{13}$ In our study, isoflurane did not seem to suppress fetal stress, as evidenced by the increase in serum fetal epinephrine levels. Although we are not aware of studies of long-term survival after fetal cardiac surgery with isoflurane, our experience suggests that the combination of inhalation of low concentration of isoflurane for mother and administration of fentanyl directly to the fetus might be a better combination in fetal cardiac surgery than either agent alone in both mother and fetus. Another alternative is a narcotic in combination with administration of nitric oxide donor to control uterine relaxation and to avoid the effect of isoflurane on the fetus. This combination may well strike the most beneficial balance of inhibition of fetal stress, uterine relaxation, and preservation of fetal myocardial function.
Further studies are needed to determine the most suitable anesthetic regimen for fetal cardiac bypass surgery.

Placental dysfunction after fetal cardiac bypass is a major obstacle to good long-term outcome. ${ }^{4,6,7,9}$ In our study, we generally could not prevent deterioration of placental gas exchange and hemodynamics even in the isoflurane group, with the exception of 1 fetus. After initiation of cardiac bypass, $\mathrm{PaO}_{2}$ was decreased, whereas $\mathrm{PaCO}_{2}$ and mean arterial blood pressure were maintained. We speculate that the acute change in $\mathrm{PaO}_{2}$ after initiation of bypass may result in part from acute hemodilution, because placental dysfunction was characterized by elevation of fetal $\mathrm{PaCO}_{2}$, indicating a decrease in placental blood flow. ${ }^{1,6}$ The deterioration in blood gas parameters was probably caused by a combination of several factors including reduced placental blood flow and reduced gas exchange in placental microvasculature. Indomethacin, ${ }^{8}$ high-dose steroid, ${ }^{6}$ and high spinal anesthesia ${ }^{4}$ have been reported as useful methods to preserve placental function in fetal cardiac bypass with ketamine anesthesia. All those studies used transfused blood for the circuit and neck cannulation with minimal fetal exposure. Although we did not use either of these approaches in our studies, 1 fetus maintained good placental function with no support methods. Comparing that fetus with other fetuses, the most different data parameter was the drastic change in hematocrit during the study. All fetuses needed continuous infusion of crystalloid during bypass to maintain adequate bypass flow and hemodynamics. Administration of crystalloid solution could probably not maintain colloidal osmotic pressure, and the infused solution was shifted to third space as edema. That edema probably contributed to the rise in placental vascular resistance through a "Starling resistor" mechanism. ${ }^{17}$ In future studies, the measurement of wet/dry weight ratios of fetus and placenta might be helpful to confirm this mechanism.

We have recently reported the successful treatment for complex cardiac disease of premature infants weighing less than $1500 \mathrm{~g},{ }^{18}$ demonstrating the feasibility of instrumentation for human fetal cardiac bypass. In a recent case of human fetal cardiac surgery with narcotic anesthesia, we successfully reduced uterine tone through infusion of the nitric oxide donor nitroglycerin (unpublished data). In both these settings, blood transfusion was necessary to maintain adequate bypass flows without significant hemodilution. Despite minimal blood loss and low pump priming volume, blood supplementation may be necessary in at least some fetal cardiac bypass cases because of the low blood volume (often less than $50 \mathrm{~mL}$ ) of the fetus. Because fetal hemoglobin exhibits a higher average affinity for oxygen than does adult hemoglobin, the adult hemoglobin level might have to be kept higher than prebypass hemoglobin level. Further studies are needed to establish optimal perioperative management in fetal cardiac surgery. 
Pump flow rate during bypass is a critical parameter for maintenance of fetal gas exchange. In our studies, we obtained a maximum flow of $176 \pm 70 \mathrm{~mL} /(\mathrm{kg} \cdot \mathrm{min})$ by using a $10 \mathrm{~F}$ venous cannula and 14 - or 16-gauge arterial cannula. The fetus was ejecting, contributing to rest of the cardiac output. The main reason for flow limitation in those experiments may simply be the size of fetus and the limited blood volume. In this study, moreover, we used a closed circuit without a reservoir to reduce priming volume and the total surface area of artificial material to prevent activation of inflammatory response. This circuit design presents a disadvantage for obtaining high pump flows, because the venous cannula sucks in the atrial wall easily. Therefore blood transfusion to the fetus, instead of only crystalloid administration, and the addition of a very small venous reservoir may be needed for safer bypass.

We have previously reported the efficacy of an inline axial flow pump in fetal cardiac bypass with a miniaturized circuit priming volume in both acute and long-term survival models. ${ }^{2,3,10}$ In our baboon studies, we did not use the axial flow pump because its minimal flow rate is too high for the circuit used in less than a $1-\mathrm{kg}$ fetus. In this study, even though we minimized the priming volume of the bypass circuit, we could not preserve satisfactory placental function except for 1 animal. Perhaps hemodilution and the third spacing of fluid were significant contributing factors to fetal hypoxia. In addition, flow hemodynamics or mechanical stimuli induced by an axial-flow pump may produce less activation of vasoconstriction cascades during bypass than seen with a roller pump. We look forward to the development of improved axial flow pumps or assist devices that better meet the specific needs of fetal cardiac surgery.

In this study, we confirmed the technical feasibility of fetal cardiac bypass in a small nonhuman primate fetus. Isoflurane anesthesia was superior to narcotic anesthesia in that it provided sustained uterine muscle relaxation. Placental dysfunction was generally not prevented in this study, and we attribute this largely to hemodilution. Although we could place the fetus on the cardiac bypass, further experimental evaluation including transfusion, anesthetic methods, and fetal exposure will be necessary to move forward to clinical use of this challenging surgical intervention.

\section{References}

1. Hanley FL. Fetal cardiac surgery. Adv Card Surg. 1994;5:47-74.

2. Reddy VM, Liddicoat JR, Klein JR, Wampler RK, Hanley FL. Longterm outcome after fetal cardiac bypass: fetal survival to full term and organ abnormalities. J Thorac Cardiovasc Surg. 1996;111:536-44.

3. Reddy VM, Liddicoat JR, Klein JR, McElhinney DB, Wampler RK, Hanley FL. Fetal cardiac bypass using an in-line axial flow pump to minimize extracorporeal surface and avoid priming volume. Ann Thorac Surg. 1996;62:393-400.

4. Fenton KN, Heinemann MK, Hickey PR, Klautz RJ, Liddicoat JR, Hanley FL. Inhibition of the fetal stress response improves cardiac output and gas exchange after fetal cardiac bypass. $J$ Thorac Cardiovasc Surg. 1994;107:1416-22.
5. Hawkins JA, Clark SM, Shaddy RE, Gay WA Jr. Fetal cardiac bypass: improved placental function with moderately high flow rates. Ann Thorac Surg. 1994;57:293-7.

6. Sabik JF, Heinemann MK, Assad RS, Hanley FL. High-dose steroids prevent placental dysfunction after fetal cardiac bypass. $J$ Thorac Cardiovasc Surg. 1994;107:116-25.

7. Carotti A, Emma F, Picca S, Iannace E, Albanese SB, Grigioni M, Meo F, Sciarra M, Di Donato RM. Inflammatory response to cardiac bypass in ewe fetuses: effects of steroid administration or continuous hemodiafiltration. J Thorac Cardiovasc Surg. 2003;126:1839-50.

8. Sabik JF, Assad RS, Hanley FL. Prostaglandin synthesis inhibition prevents placental dysfunction after fetal cardiac bypass. J Thorac Cardiovasc Surg. 1992;103:733-42.

9. Reddy VM, McElhinney DB, Rajasinghe HA, Liddicoat JR, Hendricks-Munoz K, Fineman JR, et al. Role of the endothelium in placental dysfunction after fetal cardiac bypass. J Thorac Cardiovasc Surg. 1999;117:343-51.

10. Parry AJ, Petrossian E, McElhinney DB, Reddy VM, Hanley FL. Neutrophil degranulation and complement activation during fetal cardiac bypass. Ann Thorac Surg. 2000;70:582-9.

11. Gaiser RR, Kurth CD. Anesthetic considerations for fetal surgery. Semin Perinatol. 1999;23:507-14.

12. Rosen MA. Anesthesia for fetal procedures and surgery. Yonsei Med J. 2001;42:669-80.

13. Biehl DR, Yarnell R, Wade JG, Sitar D. The uptake of isoflurane by the foetal lamb in utero: effect on regional blood flow. Can Anaesth Soc J. 1983;30:581-6.

14. Ellingson A, Haram K, Sagen N, Solheim E. Transplacental passage of ketamine after intravenous administration. Acta Anaesthesiol Scand. 1977;21:41-4.

15. Boillot A, Vallet B, Marty J, Auclerc A, Barale F. Effects of halothane, enflurane and isoflurane on contraction of rat aorta induced by endothelin-1. Br J Anaesth. 1995;75:761-7.

16. Taga K, Fukuda S, Nishimura N, Tsukui A, Morioka M, Shimoji K. Effects of thiopental, pentobarbital, and ketamine on endothelin-induced constriction of porcine cerebral arteries. Anesthesiology. 1990; 72:939-41.

17. Bissonnette JM, Farrell RC. Pressure-flow and pressure-volume relationships in the fetal placental circulation. J Appl Physiol. 1973;35: 355-60.

18. Reddy VM. Cardiac surgery for premature and low birth weight neonates. Semin Thorac Cardiovasc Surg Pediatr Card Surg Annu. 2001;4:271-6.

\section{Discussion}

Dr W. Randolph Chitwood, Jr (Greenville, $N C$ ). Tell us what you think the clinical application may be. Because this is a primate study it should have a significant clinical application. What are you planning to do from here on as far as other work in this area?

Dr Ikai. The goal of fetal cardiac surgery research is ultimately to safely intervene in utero for certain cardiac defects. The lesion for which intervention is contemplated, such as pulmonary atresia, should generally be a simple defect with severe secondary morphologic conversions. For instance, in pulmonary valve atresia enlargement of the right ventricle outflow tract may prevent hypoplasia of the right ventricle. Similarly, severe tricuspid regurgitation may result in hydrops, severe cardiomegaly, and hypoplasia of the lungs. These problems could be prevented by tricuspid repair in utero. We believe that other lesions, such as left ventricular outflow tract obstruction, restrictive patent foramen ovale, absent pulmonary valve with enlargement of pulmonary arteries, hypoplastic pulmonary arteries with major aortopulmonary collaterals, and so on could benefit from fetal intervention.

Dr Frank A. Pigula (Boston, Mass). It's fairly well known that a major obstacle to fetal bypass is placental dysfunction. Did you 
look at any parameters of placental dysfunction in this study? Did you find increases in placental vascular resistance or other markers of placental dysfunction?

Dr Ikai. We have extensively studied placental blood flow and placental vascular resistance in an ovine model. We have evaluated the benefits of indomethacin, steroids, and endothelin blockers on placental blood flow and placental vascular reactivity. In this baboon model, however, the goal was to study different anesthetics and their overall effects on fetal hemodynamics, blood gas values, and stress response.

Dr Pigula. Did you use those agents?

Dr Ikai. No, we did not. Because we wanted primarily to see the effects of anesthesia on fetal stress and fetal blood gas values, we did not use any other agents.

\section{Authoritative}

The Journal of Thoracic and Cardiovascular Surgery is the most frequently cited thoracic/cardiovascular surgery journal in the Science Citation Index. An article in JTCVS is cited on average almost twice as often as those in the closest cardiothoracic journal. 